\title{
A TEORIA ONDULATÓRIA DE HUYGENS EM LIVROS DIDÁTICOS PARA CURSOS SUPERIORES
}

\author{
The wave theory of Huygens \\ in textbooks for undergraduate courses
}

\author{
Sidney Maia Araújo ${ }^{1}$ \\ Fábio Wellington Orlando da Silva ${ }^{2}$
}

Resumo: Este trabalho compara a teoria apresentada por Christiaan Huygens no Tratado sobre a Luz, no século XVII, com a versão que aparece em alguns livros didáticos de Física para cursos superiores, e estuda a percepção dos alunos acerca do desenvolvimento dessa teoria. As informações veiculadas nesses livros incorporam contribuições posteriores, que levam a uma visão inadequada da evolução dessa teoria e a atribuir ao passado concepções atuais.

Palavras-chave: Teoria ondulatória da luz. Ensino de Física. Ensino de Ciências.

\begin{abstract}
This paper compares the theory presented by Christiaan Huygens in his Treatise on Light, in the XVII century, with the version that appears in some textbooks of Physics for undergraduate courses, and analysis the perception of students concerning the development of this theory. As a result, we found that the information presented in these books incorporated later contributions, which leads students to an incorrect view of the evolution of this theory and to attribute current conceptions to the past.
\end{abstract}

Keywords: Wave theory of light. Physics education. Science education.

\footnotetext{
${ }^{1}$ Físico. Mestrando em Educação Tecnológica. Docente, professor substituto do Centro Federal de Educação Tecnológica de Minas Gerais (CEFET/MG). Belo Horizonte, MG. <sidney.maia.araujo@gmail.com>

${ }^{2}$ Físico. Doutorado em Física. Docente, Departamento de Física e Matemática, Centro Federal de Educação Tecnológica (CEFET/MG). Belo Horizonte, MG. < fabiow@des.cefetmg.br>

${ }^{1}$ Av. Amazonas, n. 7675

Bairro Nova Gameleira - Belo Horizonte, MG

31.510-000 


\section{Introdução}

O objetivo deste artigo é comparar a teoria da luz de Christiaan Huygens (1629-1695), na forma como foi apresentada por seu autor no "Traité de la Lumière", no século XVII, om a versão que aparece em alguns livros didáticos de Física para cursos superiores, bem como estudar a percepção dos alunos acerca do desenvolvimento subsequente dessa teoria.

Os livros didáticos, durante muito tempo negligenciados por historiadores e bibliófilos, há aproximadamente trinta anos vêm despertando o interesse dos pesquisadores, passando a constituir um domínio de pesquisa (CHOPPIN, 2004). Entre os diversos aspectos analisados, merece destaque, em virtude de sua importância para a compreensão dos conceitos científicos, a incorporação de elementos da história da ciência. Nessa linha, trabalhos recentes revelam a presença, em livros de Física para o Ensino Superior, de informações distorcidas, incompatíveis com a realidade histórica, que levariam os estudantes a uma visão errônea da evolução da Física e da formulação de suas leis (CHAIB e ASSIS, 2003).

Além desses livros serem comumente adotados em diversos cursos de ciências exatas, entre eles de engenharia e licenciaturas, servem também de fonte de referência para professores e autores de livros para o Ensino Médio. Assim, as possíveis falhas cometidas nessas obras aparecem reproduzidas, com citação explícita ou não da fonte, em manuais destinados ao nível de ensino imediatamente anterior. Certamente esse fato amplia a responsabilidade, ainda que de forma indireta, com respeito aos textos adotados nos cursos superiores.

Particularmente no que se refere à teoria ondulatória da luz, a visão comumente apresentada sugere aos alunos que os pesquisadores do século XVII dispusessem, além do conhecimento resultante de desenvolvimentos posteriores, de algumas concepções atuais. Por exemplo, ao expor o Princípio de Huygens, são estudadas as propriedades periódicas, tais como o comprimento de onda e a frequência de uma onda transversal, que, além de não terem sido discutidas por ele, não se encaixam no modelo proposto. A pesquisa empírica com estudantes de engenharia mostrou também que essa aproximação entre os modelos do século XVII com a teoria eletromagnética leva, por exemplo, diversos alunos a situar Maxwell (1831-1879) no mesmo século de Huygens, eliminando, além das barreiras conceituais, as barreiras temporais.

Alguns autores têm atribuído à escola e ao ato de ensinar a fabricação de outra espécie de saber (PERRENOUD, 1993, p. 25):

Ensinar é, antes de mais, fabricar artesanalmente os saberes, tornando-os ensináveis, exercitáveis e passíveis de avaliação no quadro de uma turma, de um ano, de um horário, de um sistema de comunicação e trabalho. É o que Chevallard, na esteira de Verret, designa por transposição didática.

Assim, haveria os saberes usuais e os saberes escolares, distintos dos anteriores, oriundos de um artesanato especial. Sob esse ponto de vista, as falhas observadas seriam imputadas a incorreções ou deturpações cometidas no processo de "transposição didática".

A transposição didática é somente um entre os diversos modelos de interpretação do fenômeno escolar. Até aproximadamente 1995, ano de entrada de funcionamento comercial da web, a fabricação de manuais escolares, e de manuais para utilização de manuais, foi praticamente a única opção disponível. Talvez provenha daí a ênfase exacerbada atribuída a essa 
opção, em que o caso particular passa descrever o fenômeno geral. Após 1995, porém, a situação se modificou consideravelmente. O grande acervo de obras originais e de trabalhos de qualidade sobre a história da ciência acessíveis na internet permite que não se fique à mercê de manuais consagrados. A internet é um recurso que pode e deve ser explorado por professores e estudantes, estimulando-se, na medida do possível, a consulta às fontes primárias, inclusive para avaliar criticamente os materiais adotados. Nesse sentido, algumas tentativas de usar artigos científicos em cursos de graduação demonstraram o desenvolvimento de habilidades e a manifestação de colocações que dificilmente ocorreriam em aulas tradicionais (SANTOS e QUEIROZ, 2007).

\section{O Tratado sobre a Luz}

A contribuição de Christiaan Huygens deve ser compreendida no contexto de sua época (SILVA, 2007). O desenvolvimento da teoria física da luz durante o século XVII está associado à construção de modelos mecânicos, que procuravam explicar, por meio de conceitos puramente mecânicos, as propriedades conhecidas da luz, tais como: a propagação retilínea, a reflexão, a refração e a origem das cores. Essa busca por modelos mecânicos é facilmente compreensível, pois constituíam a melhor ciência de seu tempo. Afinal, o século XVII assistiu à publicação dos principais trabalhos de Galileu (1564-1642), Descartes (1596-1650), Pascal (1623-1662), Hooke (1635-1703), Kepler (1571-1630), Boyle (1627-1691) e Newton (1642-1727), apenas para citar os mais conhecidos. O próprio Huygens enunciou, em 1656-7, uma teoria para os choques elásticos e, em 1669, participou de um concurso realizado pela Royal Society sobre as leis do movimento, com um texto em latim, publicado no mesmo ano, em francês, no Journal des Sçavans (sic), sobre as leis do movimento nas colisões.

O Tratado sobre a Luz foi apresentado por Huygens em 1678 à Academia Real de Ciências da França, em Paris, e publicado em 1690, em Leiden, acompanhado de um discurso sobre a causa da gravidade (HUYGENS, 1937). Há uma tradução completa desse texto em português e as citações literais que aparecem neste artigo são retiradas dessa versão (HUYGENS, 1986). O Tratado é dividido em seis capítulos. Para efeito deste artigo, o mais relevante é o capítulo I, denominado "Sobre os Raios que se Propagam Diretamente", o qual apresenta alguns pressupostos e discute a natureza e as propriedades gerais da luz. Os demais capítulos tratam da reflexão, da refração, da refração no ar, da birrefringência da calcita e de um método para determinar as figuras produzidas por espelhos e lentes.

O capítulo I inicia-se com uma declaração que vincula o trabalho à tradição geométrica da Física desenvolvida no Renascimento (HUYGENS, 1986, p. 11):

Como acontece em todas as ciências nas quais a geometria é aplicada à matéria, as demonstrações relativas à Óptica são fundamentadas sobre verdades tiradas da experiência - tais como a de que os raios de luz se propagam em linha reta; que os ângulos de reflexão e de incidência são iguais; e que nas refrações o raio se desvia de acordo com a regra dos senos (agora tão conhecida) e que não é menos certa do que as precedentes. 
Quanto à natureza da luz, afirma não duvidar que consista no movimento de alguma espécie de matéria, quer se considere sua produção, quer seus efeitos. Na Terra, seria gerada, sobretudo, pelo fogo e pela chama, os quais contêm, sem dúvida, corpos em movimento rápido, pois dissolvem e fundem diversos outros corpos dos mais sólidos. No que se refere aos efeitos, se a luz for concentrada por meio de espelhos côncavos, apresentará justamente essa propriedade de queimar como o fogo, isto é, de separar as partes dos corpos, o que the confere, portanto, a marca de movimento, pelo menos no âmbito do que para ele seria a verdadeira Filosofia, na qual todos os efeitos naturais são concebidos por razões mecânicas. Acrescenta ainda que se deve proceder dessa forma ou renunciar a toda esperança de compreender qualquer coisa em Física, ou seja, deve-se adotar o modelo mecânico como a única alternativa possível.

Com respeito ao caráter ondulatório, ele faz uma analogia com as ondas sonoras no ar (HUYGENS, 1986, p. 12):

\begin{abstract}
Sabemos que, por meio do ar, que é um corpo invisível e impalpável, o som se propaga em torno do lugar onde foi produzido, por um movimento que passa sucessivamente de uma parte do ar a outra. A propagação desse movimento se faz com igual velocidade para todos os lados e devem se formar como superfícies esféricas que crescem sempre e que chegam a atingir nossas orelhas. Ora, não há dúvida de que a luz não venha do corpo luminoso até nós por algum movimento impresso à matéria que está entre os dois - pois já vimos que isso não pode ocorrer pelo transporte de um corpo que passe de um até o outro.
\end{abstract}

Nesse curto trecho, foi reafirmada a origem mecânica, a necessidade de um meio material de propagação e afastada a possibilidade de uma natureza corpuscular para a luz.

Ao considerar o som e as ondas produzidas na superfície da água pela queda de uma pedra, acredita ele, diferentemente de Descartes, que a luz tenha uma velocidade finita. Relata, em seguida, a experiência de Römer, realizada em 1676, que a avaliou em cerca de mil diâmetros da Terra por minuto, ou seja, aproximadamente $214 \mathrm{mil} \mathrm{Km} / \mathrm{h}$. Nesse aspecto, Descartes, falecido em 1650, estava em desvantagem, pois não dispunha de resultados experimentais confiáveis.

Apesar da analogia, Huygens distingue também algumas diferenças entre a luz e o som, concernente aos movimentos que os produzem, à matéria na qual se propagam e à forma como se comunicam.

Quanto ao movimento, enquanto as ondas sonoras seriam produzidas pelo tremor de um corpo inteiro, ou de uma parte considerável dele, que agita todo o ar à sua volta; a luz, ao contrário, deve nascer do movimento de cada ponto do objeto luminoso, para que se possam perceber todas as diferentes partes desse objeto. Os pontos da superfície do corpo comunicariam essa agitação aos corpúsculos do éter que os envolvem.

Essa matéria que serve à propagação da luz a partir dos corpos luminosos, ou seja, o éter, não pode ser o ar que sentimos e respiramos, pois, quando o ar é extraído de um local, o éter permanece. Isso pode ser demonstrado encerrando-se um corpo sonoro em um recipiente de vidro e retirando-se o ar por meio da bomba de vácuo inventada por Boyle. Ao retirar o 
ar, o som deixa de ser ouvido, mas a luz não deixa de atravessar o vidro, tal como antes. Da mesma forma, na experiência de Torricelli, ao inverter o tubo de vidro na cuba com o mercúrio, surge o vácuo na extremidade fechada do tubo, mas a luz continua a atravessar a porção evacuada. Isso prova que uma matéria diferente do ar deve atravessar o vidro, sabendo-se que tanto o mercúrio quanto o vidro são impenetráveis ao ar.

No que concerne à forma de propagação dos movimentos do som, afirma que o ar, em virtude de sua natureza, pode ser comprimido e, à medida que seu volume é reduzido, faz um esforço para expandir-se. Essa propriedade, associada à penetrabilidade, que permanece apesar da compressão, parece demonstrar que o ar seja constituído de pequenos corpos que flutuam e são fortemente agitados na matéria etérea, composta de partes bem menores. Assim, a causa da propagação das ondas sonoras seria o esforço de expansão realizado por esses pequenos corpos que se entrechocam, ao serem aproximados uns dos outros nesses círculos de ondas.

A extrema velocidade e outras propriedades da luz, entretanto, não admitem essa propagação de movimento. Por isso ele busca uma explicação na analogia com a transmissão do movimento entre corpos sólidos. Suponha-se um grande número de bolas de mesmo diâmetro e de material muito duro, dispostas em linha reta, coladas umas às outras. Batendo-se com uma bola semelhante a essas na primeira da fila, o movimento é transmitido rapidamente até a última, que se afasta do grupo sem que se possa perceber qualquer movimento das bolas intermediárias, permanecendo imóvel até aquela que bateu inicialmente. Essa velocidade de transmissão cresce com a dureza do material que constitui as bolas. Além disso, é importante enfatizar que a transmissão do movimento, ou da tendência ao movimento, não é instantânea, mas sucessiva, pois, se não o fosse, todas as bolas deveriam avançar ao mesmo tempo, o que não ocorre: apenas a última bola abandona a fila, e com a velocidade daquela que se chocou com a primeira.

Para relacionar esse tipo de movimento àquele que produz a luz, nada impede de estimar que esses corpúsculos se aproximem tanto quanto se queira da dureza perfeita e da elasticidade ideal. Isto sugere a idéia de os corpúsculos de éter serem compostos por outros ainda menores, cuja elasticidade seria devida a um movimento muito rápido de uma matéria sutil, que os atravessa de todos os lados, e contrai sua estrutura de forma a dar passagem a essa matéria fluida, o mais aberta e facilmente possível. Um argumento adicional para a elasticidade dos corpúsculos de éter seria a conservação da velocidade da luz. Em sua opinião, a elasticidade lhes daria a propriedade de se restituírem à posição de equilíbrio com a mesma velocidade, caso fossem fracamente ou fortemente empurradas. Assim, a luz conservaria sua velocidade à medida que se afasta da fonte.

A luz seria propagada por meio de ondas esféricas, pois os corpúsculos de éter não se encontram alinhados um após o outro, mas distribuídos de maneira confusa, de forma que cada um toque diversos vizinhos, o que não impede que transmitam o movimento e o propaguem sempre para frente. Para justificar essa asserção, mais uma o autor faz uma analogia. Considere uma bola A em contato com diversas bolas idênticas CCC. Se a bola A for atingida por uma outra bola B, de modo a pressionar todas as bolas CCC que ela toca, a bola A comunicará todo o seu "movimento" às CCC e, em seguida, A e B permanecerão imóveis (Figura 1). Nem é preciso supor que os corpúsculos de éter sejam esféricos, como na figura, embora essa característica contribua à propagação do movimento. A igualdade de dimensões, contudo, 
parece mais necessária, pois, se um corpúsculo de éter se chocasse com outro maior, haveria um pequeno recuo de parte do movimento.

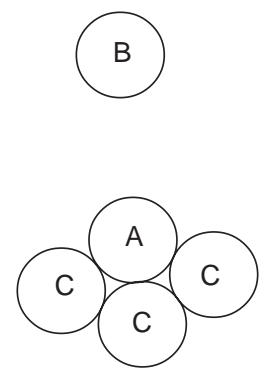

Figura 1. A bola $A$, em contato com diversas bolas idênticas $C C C$, é atingida por uma outra bola $B$. A bola A comunica o movimento às bolas $\mathrm{CCC}$ e, em seguida, as bolas A e B permanecem imóveis.

Os corpúsculos do éter são supostos em perpétuo movimento, mas a propagação sucessiva das ondas não é impedida, pois não consiste no transporte dos corpúsculos em si, apenas de uma pequena perturbação, que eles não podem deixar de comunicar aos vizinhos, apesar do movimento que os agita e os faz mudar de lugar entre si. Mais uma vez, como se percebe, uma analogia puramente mecânica.

Em seguida, Huygens passa a discutir a origem e a propagação das ondas. A construção é bastante engenhosa. Ele supõe que cada ponto de um corpo luminoso, seja do Sol, de uma lamparina, seja de um fragmento de carvão ardente, crie suas ondas, das quais o ponto é um centro de emissão (HUYGENS, 1986, p. 21):

Assim, na chama de uma vela, sendo distinguidos os pontos A, B, C, os círculos concêntricos descritos em torno de cada um desses pontos representam as ondas que deles provêm. E deve-se conceber o mesmo em torno de cada ponto da superfície e de uma parte interna dessa chama.

Uma quantidade prodigiosa de ondas se cruzam, sem confusão e sem destruir umas às outras. Um corpúsculo de matéria pode receber diversas ondas, provenientes de várias direções e até de sentidos opostos, não apenas por perturbações sucessivas, mas até simultâneas, e servir à transmissão de todas elas.

Não devemos também nos surpreender, considerando que ondulações produzidas por movimentos e por corpúsculos tão pequenos não desapareçam em distâncias tão grandes, como as existentes entre o Sol, ou as estrelas, e nós. A surpresa desaparecerá se considerarmos que, a uma grande distância do corpo luminoso, uma infinidade de ondas, apesar de saídas de pontos diferentes do corpo, unem-se de forma a comportar-se como uma única onda. E cada corpúsculo atingido pela onda comunica o movimento não apenas ao corpúsculo seguinte, em linha reta com o ponto luminoso, mas a todos da vizinhança. Com isso, em volta de cada 
corpúsculo é criada uma onda da qual esse corpúsculo é um centro. Por exemplo, seja A um ponto luminoso. Cada corpúsculo atingido pela perturbação terá sua onda particular, da qual ele é o centro. Assim, a frente de onda, no ponto mais distante de A, é resultante da contribuição de cada uma dessas ondas e da onda principal proveniente do centro luminoso. Huygens tem plena consciência das implicações desse princípio, "pois ver-se-á posteriormente que todas as propriedades da luz e tudo o que se refere à reflexão e à refração é explicado principalmente por esse meio" (HUYGENS, 1986, p. 22).

Em síntese, o Tratado sobre a Luz contém um modelo engenhoso, com muitas aplicações, mas baseado em colisões mecânicas, na transmissão da luz por choques elásticos, em consonância com seu tempo e com trabalhos anteriores do autor. Ele não menciona vibrações em torno de uma posição de equilíbrio, nem discute propriedades periódicas, tais como período, frequência ou comprimento de onda, que seriam consideradas apenas nos séculos seguintes (SHAPIRO, 1973).

\section{O Modelo de Huygens em livros didáticos}

Nesta seção será analisado como os livros didáticos das coleções de Halliday/Resnick e Tipler apresentam a contribuição de Huygens à Teoria da Ondulatória da Luz. O critério de escolha desses livros se deu por serem textos representativos, provavelmente os mais adotados no Brasil, em disciplinas iniciais de Física, pela maioria dos cursos superiores de ciências exatas. Além disso, em treze coleções de livros didáticos de Física para o Ensino Médio que foram pesquisadas (Apêndice A), esses autores aparecem explicitamente na bibliografia de 100\% daquelas que citam alguma espécie de referência, ou seja, em nove das treze, não se descartando a presença implícita nas demais. Portanto, seja do ponto de vista da formação direta do profissional de nível superior, por exemplo, engenheiro ou professor de Física, seja pela influência sobre o nível imediatamente anterior, essas duas coleções apresentam importância relevante.

\section{Halliday/Resnick}

A primeira edição foi publicada nos Estados Unidos em 1960, e a segunda em 1963, contendo 48 capítulos, cobrindo todo o programa de Física geral para estudantes de ciências e de engenharia.

Neste trabalho serão analisadas: 1 A edição de 1966 (HALLIDAY e RESNICK, 1966), tradução para o português do original em inglês (HALLIDAY e RESNICK, 1963); 2 A edição em português de 1995 (HALLIDAY e RESNICK, 1995); e 3 Fundamentos de Física (HALLIDAY, RESNICK e WALKER, 2001).

Na edição de 1966, a natureza da luz é discutida do capítulo 40 ao 47, após o estudo do Eletromagnetismo, e o estudo de ondas se dá nos capítulos 19 e 20, portanto bem afastado. O capítulo 40 (Natureza e propagação da Luz) tem início com a declaração de que Maxwell mostrou ser a luz um componente do espectro eletromagnético. O restante do capítulo trata da energia, velocidade e outras propriedades da luz, usando os vetores campo elétrico (E) e campo magnético (B). O capítulo 41 (Reflexão e refração, Ondas planas e superfícies planas) 
dá continuidade a esse estudo, afirmando que as leis da reflexão e da refração podem ser derivadas das equações de Maxwell, mas a complexidade matemática os impedirá de fazê-lo aqui, ou seja, no nível do curso. Por isso, lançarão mão de outro recurso (HALLIDAY e RESNICK, 1963, p. 1160):

Felizmente, tanto estas, quanto outras leis da óptica podem ser deduzidas de uma teoria da luz mais simples, embora mais restrita, proposta pelo físico holandês Christiaan Huygens, em 1678. Tal teoria limita-se a dizer que a luz seja uma onda em vez de, digamos, um conjunto de partículas. Nada diz sobre a natureza da luz, e, em particular - desde que a teoria de Maxwell do eletromagnetismo apareceu somente depois de decorrido mais de um século - não dá nenhuma idéia do caráter eletromagnético da luz. Huygens não sabia se a luz era uma onda transversal ou longitudinal; não conhecia os comprimentos de onda da luz visível e pouco sabia sobre a velocidade da luz.

Percebe-se aqui uma preocupação dos autores em estabelecer os limites do modelo que deverão empregar. Quanto à velocidade da Luz, é necessário reconhecer, porém, que o conhecimento de Huygens não era tão elementar. No primeiro capítulo do Tratado, ele conta que, inicialmente, considerou a velocidade da luz cerca de cem mil vezes a do som $\left(1,0 \times 10^{5}\right)$ , mas que, posteriormente, os resultados de Römer, cujo método ele relata em detalhes, permitiram-lhe avaliar em, no mínimo, $600.000\left(6,0 \times 10^{5}\right)$ essa velocidade. Esse resultado é da mesma ordem de grandeza dos números atuais $\left(8,8 \times 10^{5}\right)$. Portanto, ele conhecia a velocidade da luz com uma precisão adequada aos seus propósitos.

Em seguida, os autores enunciam o Princípio de Huygens recorrendo aos conceitos de frente de onda, fonte puntiforme e ondas esféricas. Ainda que ele não os tenha nomeado dessa forma, pode-se considerar que a obra teria estabelecido esses conceitos, representando a culminância de um esforço desenvolvido ao longo do século XVII.

As seções 41.3 e 41.3 são dedicadas, respectivamente, a obter a lei da reflexão e a lei da refração por meio do Princípio de Huygens. Em ambos os casos, as figuras ilustrativas exibem explicitamente uma distância entre as frentes de onda $(\lambda)$, o que pode ser interpretado como um comprimento de onda (Figura 2). Na refração, é demonstrada a conhecida relação entre os comprimentos de onda e as velocidades da luz nos meios inicial e final. Isso foi feito apesar de Huygens não haver discutido o comprimento de onda em sua obra, e da advertência anterior do próprio texto de que ele desconhecia esses valores. 


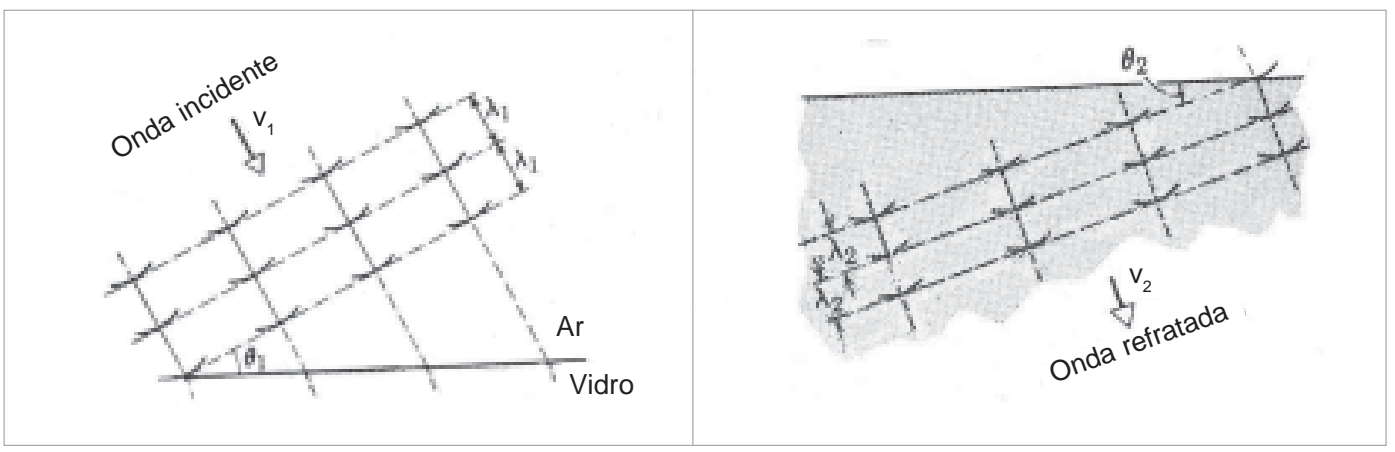

Figura 2. Ilustração do fenômeno de refração da luz, usando o Princípio de Huygens, no texto de Haliday/ Resnick (1966, p. 1165 e 1995, p. 67).

A seção 42.1 estabelece a distinção entre a Óptica Geométrica e a Óptica Ondulatória segundo o critério do efeito de difração. Na primeira, a propagação da luz poderia ser considerada em linha reta, adequadamente descrita por raios luminosos; na segunda, a natureza ondulatória da luz deveria ser explicitamente considerada, podendo ocorrer fenômenos de difração. A difração da luz em um orifício é então explicada por meio do Princípio de Huygens, e as dimensões do orifício são expressas em termos do comprimento de onda, tanto no texto, quanto nas figuras. Além disso, há ilustrações de difração em um tanque de água, com o qual são feitas algumas analogias, sem qualquer referência às diferenças dos tipos de onda envolvidos nos dois casos (longitudinal/transversal).

O capítulo 46 é dedicado à Polarização. Na seção 46.4, que trata da dupla refração, pode-se ler: "Se os dois raios emergentes na Fig. 46.11 forem analisados com um polarizador, encontra-se que eles são plano-polarizados, com seus planos de vibração em ângulos retos um com o outro, um fato descoberto por Huygens em 1678" (HALLIDAY e RESNICK, 1963, p. 1164). A figura seguinte, a 46.12, apresenta claramente uma direção de propagação da luz e dois planos de vibração perpendiculares a essa direção, correspondentes aos dois tipos de raios que emergem da calcita. Essa afirmação levaria a crer que, naquela época, Huygens já tivesse consciência da polarização plana, o que não se justifica com base nos textos originais estudados, pois: (1) ele não trata a luz em termos vibratórios; (2) em consequência, não discute se ela seria do tipo longitudinal ou transversal, e, em decorrência dos anteriores, (3) não tinha conhecimento da existência da luz plano-polarizada.

Considerando-se que o movimento, ou a tendência ao movimento, das partículas de éter no modelo de Huygens é sempre paralelo à direção de propagação da luz, o tipo provável dessa onda seria longitudinal. Não foi por acaso que o registro da polarização por reflexão por Malus, no século XIX, criou uma dificuldade adicional para os defensores da teoria ondulatória. É correto dizer que o fenômeno da dupla refração foi discutido no Tratado, e por meio de uma explicação elegante, mas não em termos de uma onda plano-polarizada, como supõe o livro didático. A esse respeito, aliás, o próprio Huygens (1986, p. 74) afirmou: "Mas não encontrei até agora nada que me satisfaça para indicar como isso ocorre.” Essa frase foi mencio- 
nada por Newton (1996, p. 266-7) em seu livro "Óptica" e usada para expor o que ele considerava uma dificuldade em considerar a luz apenas uma pressão ou movimento propagados através do éter.

A descrição sugerida nas figuras é confirmada pelo texto, segundo o qual a dupla refração ocorreria de acordo com o mecanismo: 1 O cristal divide o feixe de luz em duas componentes que percebem índices de refração diferentes ao longo da estrutura cristalina da calcita; 2 Surgem então duas frentes de ondas, que se propagam com velocidades diferentes, produzindo, assim, frentes esferóides e elipsóides; 3 Cada frente de onda representa um estado diferente de polarização da luz. Assim, o Princípio foi empregado para explicar a divisão da frente de ondas, que corresponderiam a diferentes polarizações da luz.

A edição de 1995 apresenta alterações em relação à anterior. Permanece a afirmação de que se trata de uma teoria menos compreensível do que a de Maxwell, apesar de matematicamente mais simples. Entretanto, desapareceram os comentários sobre algumas limitações. Não menciona mais o problema relativo ao tipo de onda (transversal ou longitudinal), não afirma explicitamente que o autor não tinha idéia do caráter eletromagnético da luz, não comenta a ausência dos comprimentos de onda, nem da velocidade no modelo original. Logo em seguida, repete-se o tratamento das primeiras edições, ou seja, usando as propriedades periódicas, tanto no texto quanto nas figuras.

A passagem da teoria desenvolvida no século XVII ao século XIX é muito mais suave do que indicariam as fontes históricas. Por exemplo, na seção 41.1, com respeito à difração, encontra-se (HALLIDAY e RESNICK, 1995, p. 89):

Hoje, o fenômeno da difração pode ser explicado facilmente pela Teoria Ondulatória da Luz. Esta teoria, desenvolvida inicialmente por Huygens e usada por Young para explicar a interferência numa fenda dupla, levou muito tempo para ser adotada, em grande parte porque ela entrava em choque com a Teoria de Newton.

Ao afirmar que a não aceitação, durante muito tempo, da teoria ondulatória teria ocorrido em grande parte porque ela entrava em choque com a teoria de Newton, sem discutir as dificuldades de suas versões iniciais, desloca-se a origem do problema. Ele deixa de ser uma busca para superar as dificuldades inerentes ao modelo, e passa a ser uma disputa de autoridade.

No fim da seção, há uma referência ao trabalho de Fresnel. Apesar de fazer parte explicitamente de um desenvolvimento posterior, cremos oportuno citar uma falha ao comentar o 'ponto brilhante de Fresnel'. O texto afirma que "deveria aparecer um ponto brilhante ('spot') no centro da sombra de uma esfera", o que é repetido na figura que ilustra a seção. $O$ texto de Arago (1855), comentando o experimento de Fresnel, não se refere a uma esfera, mas a um anteparo opaco circular.

Em resumo, as duas edições contêm afirmações incompatíveis com as informações obtidas em fontes primárias. A versão de 1995, ainda mais que a anterior, sugere uma visão bem mais atual da teoria. Por exemplo, afirmar que ela é menos compreensível que a de Maxwell é diferente de afirmar categoricamente que seu autor não fazia a menor idéia das ondas eletromagnéticas. Comparando as duas edições do Halliday, tem-se a impressão de que a Teoria da Luz de Huygens evoluiu consideravelmente nos últimos trinta anos. 
A teoria ondulatória de Huygens ...

\section{Tipler}

A coleção do Tipler surgiu inicialmente com o título de "Física", publicada no Brasil pela LTC-Livros Técnicos e Científicos Editora S.A. Posteriormente, foi denominada "Física para engenheiros e cientistas", podendo ser encontrada em duas versões, uma com 35 e outra com 42 capítulos, em quatro volumes, em diversas edições. Os capítulos adicionais da versão mais recente referem-se à Física Moderna, que não serão objeto deste estudo. Neste trabalho, foram analisadas uma edição de 1978 (TIPLER, 1978), em dois volumes, e uma de 1995 (TIPLER, 1985), em quatro, ambas com um total de 42 capítulos. A principal diferença entre as duas edições se refere à redistribuição dos conteúdos. Os textos da edição de 1978 analisados neste trabalho se encontram no volume 2, particularmente os capítulos 25 - Propagação de Ondas e 26 - Luz; da edição de 1995, estão no volume 4, particularmente os capítulo 30 (Luz) e 33 (Interferência e Difração).

Diferentemente do Halliday/Resnick, essa coleção aproxima o estudo da luz do estudo de ondas. Se, por um lado, essa disposição é mais coerente com o tratamento dado por ambos os textos (analogia mecânica), por outro, a influência da representação gráfica da parte de mecânica ondulatória sobre a visualização dos fenômenos luminosos é maior nesse último, em virtude da proximidade.

Iniciaremos com a edição de 1978. No capítulo 25, após descrever o fenômeno da difração de ondas planas em um tanque de água (seção 25.1), o Princípio de Huygens é apresentado (Seção 25.2), fazendo referência ao texto de 1678 e a um refinamento de Kirchhoff, do século XIX, relativo à direção do ângulo de propagação. Não se menciona que o Princípio teria sido proposto inicialmente para a luz, considerada então uma onda mecânica longitudinal como o som. Ao apresentar o princípio logo após a abordagem do movimento ondulatório, sem discutir a idéia de onda que teria orientado o trabalho de Huygens, o aluno é induzido à compreensão errônea de que ele se aplica a ondas em geral e, em particular, a uma onda transversal na forma como a concebemos hoje. Historicamente, ocorreu o contrário, ele foi concebido para explicar os fenômenos luminosos, interpretados como ondas de choque, longitudinais, e, posteriormente, foi estendido a outras espécies. A presença do experimento com tanque de água reforça esse ponto e transmite a impressão de que realmente se referia a ondas transversais, não longitudinais. Sabe-se que a analogia com as ondas em um tanque aparecem em um trabalho de Young, mas inclusive para ele a possibilidade de que a luz fosse uma onda transversal só lhe ocorreu em 1817. Ao justapor as informações, dissolve-se a distância entre os séculos.

Em seguida, o princípio será usado para explicar os fenômenos de difração, reflexão e refração, todos eles tendo como exemplo as ondas na água.

O capítulo 26 apresenta uma descrição sumária das principais concepções históricas sobre a luz, enfatizando a teoria corpuscular, cujo proponente mais importante seria Newton, e a teoria ondulatória, que teria como principais defensores Huygens e Hooke. Os fenômenos de difração e a lei da refração são explicados invocando-se o princípio de Huygens, como fora feito no capítulo anterior, cujos resultados seriam válidos para qualquer tipo de onda.

Quanto às ilustrações, o autor teve o cuidado de não apresentar nem o comprimento de onda (ë), nem a velocidade (v), e abordou uma construção circular e paralela para as frentes de onda. Contudo, de um total de 56 figuras relativas a ondas, quatro são representações 
longitudinais $(7,1 \%), 17$ são de frentes de onda que podem ser tanto para ondas longitudinais quanto transversais $(30,4 \%)$, e a maioria são ondas transversais $(62,5 \%)$. Isso pode induzir o aluno a uma associação cognitiva preferencial para o tipo de ondas transversais.

A versão de 1995 apresenta algumas modificações. Após a síntese histórica já referida, a Seção 30.2 afirma que o Princípio de Huygens seria um método geométrico criado em 1678, enunciado nos seguintes termos (TIPLER, 1995, p. 33):

Cada ponto de uma frente de onda primária serve como fonte puntiforme de ondículas secundárias esféricas que avançam numa velocidade e numa freqüência igual à velocidade e à freqüência da onda primária. A nova frente de onda primária, num instante posterior, é a envoltória das ondículas.

Dessa forma, o autor do Princípio teria discutido, em seu Tratado, os conceitos de velocidade e de frequência. Tal como na versão anterior, nenhuma ressalva é feita ao tipo de onda que ele pretendia descrever. A referência ao conceito de 'frente de onda' nesta versão é diferente da anterior. Se é verdade que boa parte do Tratado pode ser considerada uma elaboração desse conceito, ele não foi explicitamente nomeado como tal. Na versão anterior, aparece como uma explicação do conceito; aqui, aparece como se assim estivesse nomeado no texto original.

Em seguida, é comentada a modificação do princípio por Fresnel, que teria introduzido as amplitudes relativas e as fases das ondas. Essa observação tem a vantagem de reconhecer, pelo menos de forma implícita, que doravante será utilizada a versão modificada, não a original.

Por exemplo, na seção 33.7 (Figura de Difração numa Fenda Simples), a discussão quantitativa é feita admitindo-se uma divisão da fenda em $\mathrm{N}$ intervalos iguais, com uma fonte puntiforme de ondas no centro de cada intervalo. Na seção 33.9 (Difração de Fraunhofer e Difração de Fresnel), os autores afirmam que, para obter a equação da seção 33.7, admitiram que "as amplitudes e as fases das diversas fontes de Huygens eram iguais" (TIPLER, 1995, p. 124).

Ao fim do capítulo, há um tópico facultativo sobre a dupla refração no cristal de calcita. Assim como o Halliday/Resnick, esse autor mescla alguns elementos originais de Huygens com outros posteriores, fazendo uma transposição didática que não corresponde à visão atual da ciência, nem aos modelos individuais em que se apóia para construir sua explicação.

No que se refere ao famoso ponto de Fresnel, eles mencionam "a figura de difração de Fresnel num disco opaco iluminado por uma fonte de luz colocada no seu eixo". Talvez por considerarem redundante, não esclarecem que o disco devia ser circular, nem no texto principal, nem na figura de ilustração, a Fig. 33.29 (a). Entretanto, essa figura contém uma parte (b): enquanto a primeira exibe o ponto brilhante de Fresnel, a segunda mostra a "Difração de Fresnel por uma abertura circular", com um ponto escuro no centro da abertura. 
A teoria ondulatória de Huygens ...

\section{A percepção dos estudantes do modelo de Huygens}

Adotando-se a premissa de que o texto didático adquire importância na medida em que contribui para o aprendizado dos alunos, será necessário verificar a posteriori, após frequentar um curso ou uma disciplina, a imagem dos conceitos construídos.

Com o objetivo de avaliar o conhecimento dos estudantes acerca da natureza da luz no século XVII, realizamos uma pesquisa com estudantes de engenharia mecânica e de engenharia elétrica de duas escolas de Belo Horizonte. Na escola 1, participaram 26 estudantes de uma turma mista de engenharia mecânica e de engenharia elétrica. $\mathrm{Na}$ escola 2, participaram 18 estudantes de engenharia elétrica e 21 de engenharia mecânica.

O instrumento utilizado foi um questionário de 12 questões precedidas por uma explicação acerca do objetivo da pesquisa (Apêndice B). Na explicação, são expostos os objetivos do questionário, ou seja, avaliar o conhecimento do aluno a respeito da teoria corpuscular e da teoria ondulatória desenvolvidas no século XVII. As duas primeiras questões destinam-se a determinar se o aluno já estudou a natureza da luz e em qual livro texto. A terceira questão pede para se especificar a natureza de uma onda luminosa de acordo com a Física Atual. As questões seguintes referem-se à autoria e características dos dois modelos em pauta no século XVII. Em todas as questões, tomou-se o cuidado de enfatizar que elas deveriam ser respondidas de acordo com a teoria ondulatória da luz do século XVII.

Considerando que Huygens é o único autor do século XVII cuja teoria ondulatória da luz foi discutida nos livros adotados, para efeito deste questionário foram consideradas respostas corretas aquelas que estivessem em coerência com sua obra. Além disso, ele pode ser considerado representativo dessa fase pelos seguintes motivos: (1) incorpora, de forma crítica, as principais contribuições de seus predecessores; (2) representa o ponto culminante do modelo mecanicista da época; (3) contém um princípio relevante e original, largamente difundido.

Os resultados obtidos na escola 1 foram surpreendentes, pois praticamente todos os alunos assinalaram ou que não haviam estudado, ou que não se lembravam da natureza da luz. Como seria de se esperar, as respostas às questões seguintes se distribuíram aleatoriamente $\mathrm{e}$ não revelaram nenhum padrão. O coordenador do curso informou que essa escola, em consonância com sua opção pedagógica, não exige que os professores ministrem integralmente a ementa das disciplinas. A obrigatoriedade em cumprir a ementa caracterizaria uma tradição "conteudista" de ensino, incompatível com a opção adotada, ainda que possa conduzir ao estranho fato de os estudantes de engenharia, no $5^{\circ}$ período do curso, desconhecerem algumas características elementares da natureza da luz.

As respostas fornecidas pelos estudantes da escola 2 foram bem diversas daquelas da anterior e estão no Apêndice C. Apesar de algumas variações nos percentuais das alternativas assinaladas pelos estudantes de engenharia mecânica e de engenharia elétrica, a tendência de modo geral é a mesma. Acima de $75 \%$ da turma afirmaram ter estudado sobre a natureza da luz, e o livro texto mais usado foi o Tipler. Para a grande maioria, a concepção atual da onda luminosa é eletromagnética, apesar de ficarem em dúvida em the atribuir um caráter longitudinal ou transversal. No que se refere à representação gráfica, cerca de $50 \%$ dos alunos atribuíram ao século XVII a conhecida ilustração de uma onda eletromagnética transversal. Apenas uma minoria (em torno de 25\%) associou o nome de Newton à teoria corpuscular da luz, o qual foi apontado, juntamente com Snell, como um dos pesquisadores que abordaram as pro- 
priedades ondulatórias da luz. Chama ainda a atenção o fato de cerca de um terço dos alunos situar Maxwell no século XVII, portanto contemporâneo de Huygens, ignorando os mais de duzentos anos que separam os dois nascimentos e as consequentes alterações de visão do mundo.

Quanto ao mecanismo de propagação da luz, a transmissão da perturbação de uma partícula à partícula seguinte sem oscilar, conforme foi proposto por Huygens naquele época, cuja princípio supostamente estudaram, não foi a alternativa mais assinalada em nenhuma das turmas, talvez por estar muito distante da concepção atual de uma onda. Coerentemente, a grande maioria não assinalou a exigência de um meio material para a propagação da onda luminosa, e escolheu a figura representando dois campos perpendiculares, elétrico e magnético, como o do modelo que mais se aproxima da proposta do século XVII. Dessa forma, o debate acerca da existência do éter, que se estendeu até o século XX, já estaria superado três séculos atrás. Observou-se uma reafirmação da mensagem dos livros didáticos, que discutem as propriedades periódicas da luz a partir do modelo de Huygens.

Quanto à distinção entre os alunos que estudaram nos livros de Halliday/Resnick ou Tipler, a maioria dos alunos (mais de 70\%) usou esse último, mas as demais respostas não apresentaram diferenças significativas. É necessário assinalar que, apesar desses alunos terem estudado com professores distintos, o que poderia gerar diferenças de abordagem, o conteúdo histórico dos dois livros é muito semelhante, distinguindo-se apenas em alguns detalhes.

\section{Conclusão}

A apresentação do Princípio de Huygens foi analisada em dois livros de Física relevantes para os cursos superiores, que são referência bibliográfica de obras dirigidas ao Ensino Médio.

A teoria ondulatória da luz do século XVII apresentada nesses textos, particularmente o Princípio de Huygens, contém ou sugere que os pesquisadores daquele século dispusessem do conhecimento resultante de desenvolvimentos posteriores e de algumas concepções atuais. Por exemplo, ao expor o Princípio de Huygens, são estudadas propriedades periódicas, tais como o comprimento de onda e a freqüência de uma onda transversal, que, além de não terem sido discutidas por ele, não se encaixam no modelo proposto.

A pesquisa empírica com estudantes de engenharia mostrou também que essa aproximação entre os modelos do século XVII e a teoria eletromagnética atual leva os estudantes a eliminarem, além das barreiras conceituais, as barreiras temporais. Em consequência, diversos alunos situaram Maxwell no mesmo século de Huygens.

A análise sugere ainda que os autores pretendam tomar o Princípio de Huygens como um conceito que evoluiu e se transformou ao longo do tempo, assim como os de luz, onda ou éter. Estudar essa evolução, correlacionando-a com as principais concepções vigentes em cada época, pode ajudar a perceber a ciência de forma mais abrangente. Por exemplo, o estudo da luz, no século XVII, seria relacionado ao modelo mecânico; no século XVIII, ao modelo hidráulico-termodinâmico (fluxo); a partir do século XIX-XX, à teoria de campo. Entretanto, não explicitar que se fez uma reconstrução da teoria exposta no Tratado da Luz, e ignorar as 
A teoria ondulatória de Huygens ...

diferenças interpretativas características de cada época, impondo-lhe uma versão atual, conduz a uma visão deformada da evolução da ciência.

Este trabalho baseou-se na comparação entre o conteúdo de duas coleções de livros usualmente adotadas em nossas escolas e fontes primárias disponíveis na internet. Isso demonstra que a internet é um recurso que pode e deve ser empregado pelos professores, dispensando-se, em grande parte, a fabricação de fontes secundárias, passíveis de falhas e deturpações, como se fosse outro saber, o saber escolar.

\section{Referências}

ARAGO, F. Oeuvres complètes de François Arago, secrétaire perpétuel de l'académie des sciences. Mémoires scientifiques, Paris/Leipzig, v. 1, n. 10, p. 375-86, 1855. Disponível em: <http://gallica.bnf.fr/ark:/12148/bpt6k92716m>. Acesso em: 27 out. 2007.

CHAIB, J. P. M. C.; ASSIS, A. K. T. Distorção da obra eletromagnética de Ampère nos livros didáticos. Revista Brasileira de Ensino de Física, São Carlos, v. 29, n. 1, p. 65-70, 2007. Disponível em: <http://www.sbfisica.org.br/rbef/indice.php?vol=29\&num=1>. Acesso em: 10 jul. 2007.

CHOPPIN, A. História dos livros didáticos e das edições didáticas: sobre o estado da arte. Educação e Pesquisa, São Paulo, v. 30, n. 3, p. 549-66, 2004. Disponível em: <http:// www.scielo.br/scielo.php?script $=$ sci_issuetoc\&pid $=1517$ -

970220040003\&lng=pt\&nrm=iso >. Acesso em: 10 jul. 2007.

HALLIDAY, D.; RESNICK, R. Física. Rio de Janeiro: Livros Técnicos e Científicos Editora, 1995.

;___ Física. Rio de Janeiro: Livros Técnicos e Científicos Editora, 1966.

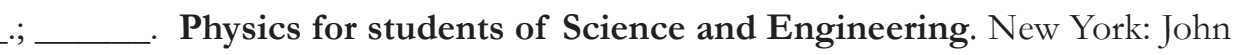
Wiley \& Sons, 1963.

HALLIDAY, D.; RESNICK, R.; WALKER, J. Fundamentos de Física. Rio de Janeiro: Livros Técnicos e Científicos Editora, 2001.

HUYGENS, C. Traité de la Lumière. Haia: Martinus Nijhoff, 1937. Disponível em: <http://gallica.bnf.fr/ark:/12148/bpt6k77868x>. Acesso em 23 out. 2007.

. Tratado sobre a luz. Trad. Roberto de A. Martins. Cadernos de História e

Filosofia da Ciência, Campinas, Suplemento 4, p. 1-99, 1986.

NEWTON, I. Óptica. Trad. André Koch Torres Assis. São Paulo: Editora da USP, 1996.

PERRENOUD, P. H. Práticas pedagógicas e profissão docente: Três facetas. In:

Práticas pedagógicas, profissão docente e formação: perspectivas sociológicas. Lisboa: Dom Quixote, 1993. p. 17-31. 
Araújo, S. M.; Silva, F. W. O.

SANTOS, G. R.; QUEIROZ, S. L. Leitura e interpretação de artigos científicos por alunos de graduação em Química. Ciência \& Educação, Bauru, v. 13, n. 2, p. 193-209, 2007.

Disponível em: <http://www.scielo.br/scielo.php?script=sci_issuetoc\&pid=1516-

$731320070002 \& \operatorname{lng}=$ en\&nrm=iso > . Acesso em: 27 set. 2007.

SHAPIRO, A. E. Kinematic optics: a study of the wave theory of light in the seventeenth century. Archive for History of Exact Sciences, Berlim, v. 11, n. 2-3, p. 134-266, 1973.

SILVA, F. W. O. A evolução da teoria ondulatória da luz e os livros didáticos. Revista

Brasileira de Ensino de Física, São Carlos, v. 29, n. 1, p. 151-61, 2007.

TIPLER, P. Física. Rio de Janeiro: Livros Técnicos e Científicos Editora, 1995.

Física. Rio de Janeiro: Livros Técnicos e Científicos Editora, 1978.

Apêndice A - Coleções didáticas para o ensino médio analisadas

AlVARENGA, B. A.; LUZ, A. M. R. Curso de Física. São Paulo: Scipione, 2006.

CABRAL, F.; LAGOS, A. Física. São Paulo: Harbra, 2002.

FERRARO, N. et al. Física: Ciência e Tecnologia. São Paulo: Moderna, 2001.

FERRARO, N. G.; TOledo, P. A. Aulas de Física. São Paulo: Atual, 2003.

GASPAR, A. Física. São Paulo: Ática, 2001.

HAMBURGER, E. et al. São Paulo: Telecurso 2000, 2002.

HELOU, R. H.; VILLAS BOAS, N.; GUALTER, J. Tópicos de Física. São Paulo: Saraiva, 2001.

LEITE, C.; PINTO, A. C.; SILVA, J. A. Física. São Paulo: Brasil, 2005.

PENTEADO, P. C. M. Física: conceitos e aplicações. São Paulo: Moderna,1998.

RAMALHO, F.; FERRARO, N. G.; TOLEDO, P.A. Os fundamentos da Física. São Paulo: Moderna, 2003.

SAMPAIO, J. L.; CALÇADA, C. S. Universo da Física. São Paulo: Atual, 2001.

SHIGEKIYO, C. T.; YAMAMOTO, K.; FUKE, L. F. Os alicerces da Física. São Paulo: Saraiva, 1998.

SILVA, D. N. Física. São Paulo: Ática, 1999. 


\section{Apêndice B - Questionário sobre a teoria ondulatória da luz}

Os livros de Física costumam opor duas teorias distintas para explicar a natureza da luz: a teoria corpuscular e a teoria ondulatória. Essas teorias, desenvolvidas na segunda metade do século XVII, diferem em alguns aspectos essenciais e buscam, cada uma a seu modo, explicar os fenômenos ópticos observáveis. O presente questionário pretende investigar o seu conhecimento a respeito dessas teorias formuladas nesse período histórico e sua relação com os fenômenos ópticos.

1) Você se lembra de ter estudado ótica geométrica e óptica física (natureza da luz)?

a) Sim, apenas o primeiro.

b) Sim, os dois.

c) Não, nunca estudei.

d) Sim, mas já me esqueci do que se trata.

2) Qual o livro-texto usado por seu professor para tratar do tema: "Óptica e movimento ondulatório"?

a) Física ou Os Fundamentos da Física, Halliday/Resnick

b) Física para cientistas e engenheiros, Paul Tipler

c) Física, Sears/Young/Zemansky

d) Outro. Qual?

3) De acordo com a óptica física atual, qual é a natureza de uma onda luminosa?

a) eletromagnética/ transversal

b) mecânica/ transversal

c) mecânica/ longitudinal

d) eletromagnética/ longitudinal séc.XVII?

4) Qual (is) do(s) nome(s) abaixo você associa com estudos sobre a teoria corpuscular da luz do
a) Newton
b) Huygens
c) Snell

d) Fresnell do séc.XVII?

5) Qual (is) do(s) nome(s) abaixo você associa com estudos sobre a natureza ondulatória da luz
a) Newton
b) Huygens
c) Snell
d) Maxwell

6) As propriedades ondulatórias da luz (frequência, período, comprimento de onda) foram abordadas pelo(s) seguinte(s) cientista(s):
a) Huygens
b) Newton
c) Snell
d) Fresnell

7) De acordo com a teoria ondulatória da luz do séc. XVII, ao ser atingida por uma onda luminosa, uma partícula deveria:

a) oscilar em torno de sua posição de equilíbrio até parar.

b) oscilar indefinidamente em torno de sua posição de equilíbrio.

c) transferir a perturbação recebida à partícula seguinte, sem oscilar.

d) refletir a perturbação de volta à partícula inicial.

8) De acordo com a teoria ondulatória da luz do séc. XVII, uma onda luminosa para se propagar:

a) necessita de um meio material elástico.

b) necessita de um meio material não elástico.

c) necessita de um meio material, mas não especifica suas propriedades.

d) não precisa de meio material, propagando-se também no vácuo. 
Araújo, S. M.; Silva, F. W. O.

9) Entre as figuras abaixo, representando ondas, escolha a que mais se aproxima do modelo da luz proposto pela teoria ondulatória do séc.XVII:

a)

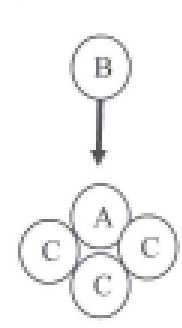

$\mathrm{A}, \mathrm{B}$ e C sâo particulas

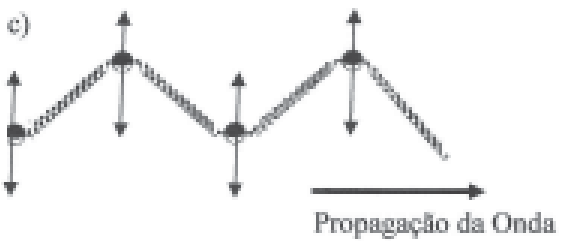

b)

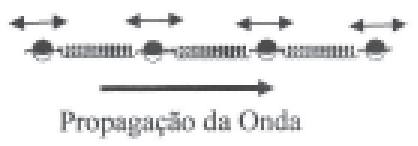

d)

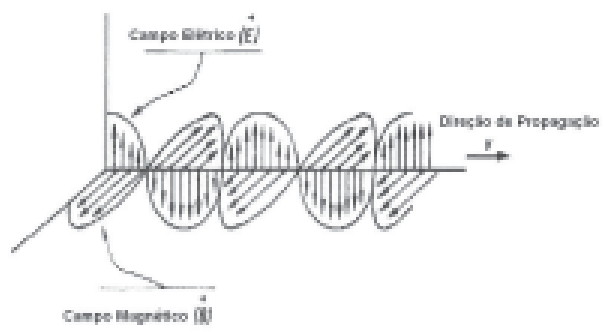

10) De acordo com a teoria ondulatória do século XVII, as ondas luminosas, durante a sua propagação, se comportam como:

a) diversas fontes de onda secundária, que oscilam com a mesma frequência da fonte primária. primária.

b) diversas fontes de onda secundária, que oscilam com uma frequência menor do que a da fonte primária.

c) diversas fontes de onda secundária, que oscilam com uma frequência maior do que a da fonte

d) diversas fontes de onda secundária, mas não discute sua frequência.

11) De acordo com a teoria ondulatória da luz do séc. XVII, um raio de luz, ao passar pela interface de um meio mais denso para um meio menos denso, ambos transparentes, deveria:

a) mudar sua velocidade de propagação, com velocidade maior no meio mais denso.

b) mudar sua velocidade de propagação, com velocidade menor no meio mais denso.

c) mudar sua direção de propagação e sua velocidade, qualquer que fosse a incidência da luz.

d) mudar sua direção de propagação, mantendo a mesma velocidade.

12 ) A observação da polarização por reflexão de um feixe de luz no séc. XIX contribuiu para o fortalecimento da versão:

a) original da teoria ondulatória da luz do séc. XVII.

b) original da teoria corpuscular da luz do séc. XVII.

c) do séc. XVII da teoria ondulatória da luz, porém com modificações na proposta inicial.

d) do séc. XVII da teoria corpuscular da luz, porém com modificações na proposta inicial. 
A teoria ondulatória de Huygens ...

Apêndice C - Respostas às questões sobre a teoria ondulatória da luz, do Apêndice $B$, fornecidas pelos estudantes da Escola 2

Turma de Engenharia Mecânica

\begin{tabular}{lrrrrr}
\hline Questão & A\% & B\% & C\% & D\% & Não marcou \% \\
\hline 1 & 0 & 76,2 & 0 & 19 & 4,8 \\
2 & 19 & 71 & 4,8 & 4,8 & 4,8 \\
3 & 28,6 & 9,5 & 57,1 & 4,8 \\
4 & 23,8 & 4,8 & 38,1 & 9,5 & 23,8 \\
5 & 23,8 & 9,5 & 23,8 & 33,4 & 9,5 \\
6 & 19 & 23,8 & 9,6 & 28,6 \\
7 & 19 & 28,6 & 47,6 & 0 \\
8 & 0 & 0,8 & 9,5 & 90,5 & 0 \\
9 & 0 & 14,3 & 38,1 & 47,6 & 0 \\
10 & 28,5 & 52,4 & 4,8 & 9,5 & 4,8 \\
11 & 9,5 & 33,3 & 28,6 & 28,6 & 0 \\
12 & 28,5 & 14,3 & 47,6 & 4,8 & 4,8 \\
\hline
\end{tabular}

Turma de Engenharia Elétrica

\begin{tabular}{lrrrrr}
\hline Questão & A\% & B\% & C\% & D\% & Não marcou \% \\
\hline 1 & 0 & 77,8 & 0 & 22,2 & 0 \\
2 & 5,6 & 72,2 & 22,2 & 0 & 0 \\
3 & 50 & 0 & 0 & 50 & 0 \\
4 & 27,8 & 5,6 & 44,4 & 5,6 & 16,7 \\
5 & 22,2 & 22,2 & 38,2 & 33,3 & 0 \\
6 & 11,1 & 38,9 & 22,2 & 11,1 & 0 \\
7 & 33,3 & 22,2 & 22,2 & 0 \\
8 & 5,6 & 0 & 22,2 & 61,1 & 0 \\
9 & 11,1 & 16,7 & 0 & 50 & 0 \\
11 & 72,2 & 22,2 & 5,3 & 33,3 & 0 \\
12 & 0 & 50 & 36,7 & 5,6 & 0 \\
\hline
\end{tabular}

Artigo recebido em novembro de 2008 e aceito em maio de 2009. 